\title{
Ethos, logos and pathos - the makings of a great research paper?
}

\section{Elizabeth Kay}

Readers of Evidence-Based Dentistry are very aware that there are clear criteria and robust processes by which the strength of the evidence presented in a research paper, should be judged. Those methodologies, and ways of having clarity about what is 'good' and what is 'bad' science are absolutely central to the Journal's purpose and will always remain the foundation of what we do.

However, the other day, I was contemplating the aspects of a paper which would make it compelling, interesting, memorable and exciting to the reader. And during my reverie, it occurred to me that those papers that really make one sit up and take notice have a good deal more about them than just good science, high quality data and excellent analyses. The papers that really 'float one's boat' have other qualities. A really great paper, for most of us, will begin by convincing the reader that the author really knows what they are talking about and that they have definite grounds for authority on the subject. The author will also, somehow, persuade us that they understand what is important to us, the readers. These outcomes are achieved in various ways, among them, writing wellconstructed sentences, being grammatically correct, and providing a succinct and insightful, yet comprehensive overview of the current state of knowledge and relevant literature and placing the current 'state of the art' and the proposed research question into the context of our day to day lives. Finally, and importantly, the author will engender a sense that the research question is truly of importance to them. It is not always clear to me how authors do this. I think there are probably various means of provoking this sense of trust in the reader, but when it is achieved the reader will be sure that the paper is going to be really interesting and very probably important for them to understand.

So, the next part of a great research paper will then, having already obtained ones full and undivided attention, present excellent, logical methodologies, well-documented and tabulated results, and data which truly sheds light on the question being posed. This part of research papers, in my experience, is almost always done well. That is because dentistry is now well versed in the importance of good study design and the requirements of first class research (which are, incidentally, becoming increasingly stringent).

But after the exposition and analysis of the data, there is something else which raises a paper from being a passable and publishable piece of research, to being a powerful and persuasive piece which will influence and improve policy or practice. That 'something else' is the part that makes us feel that the findings of the paper 'matter'. Really matter. So, the discussion and conclusion of the type of paper I am talking about will provoke a response that chimes with the reader's feelings about the subject. The author will interpret the data in a way which appeals to (or undermines) the readers belief that dentistry is about looking after people, creating health and well-being, making the world better. That is, a good paper will elicit feelings which already reside in the reader, and help them to confirm or deny the beliefs that underlie their feelings about the subject.

And so, my proposition to you is that a really persuasive research paper has three core qualities. Firstly, it makes us believe that it comes from a convincing source which has credibility and integrity, and no vested interest or ulterior motive. Secondly, an excellent paper will present facts and figures in a logical manner, and will analyse them in a rational and meaningful way. Thirdly, and finally, the outstanding paper, the paper that you will remember, will create an emotional response and this will be done through the telling of a very convincing story.

And all of the above are exactly what Evidence-Based Dentistry tries to do. We try to enhance the central qualities of important papers in every single review that we publish. Our excellent commentators set the findings of our research colleagues in a meaningful context, they unravel increasingly complex data sets and they make sense of ever more esoteric computer driven analyses. Lastly, and I believe very importantly, they help us to understand why a paper matters (or, on occasion, why it does not!). What our reviewers do, as well as sifting through the science of the evidence presented, is to expose to our readership that the science was designed and the study carried out because someone, somewhere, had noticed something unexpected, or felt curious as to why things are the way they are. Researchers are people who want to help those who were asked a question and found they did not have the answer, and our commentators, hopefully, bring to light this real human perspective underlying all really important research.

Undertaking this task fulfils, we believe, a hugely important role, and one which in the coming years, I wish to develop and grow so that this journal becomes even more participatory, and even more of a 'two way street' - because, without knowing your responses to our content we cannot know whether we are making any sort of difference. Which, as I have mentioned a number of times before, is what we all want to do.

Evidence-Based Dentistry (2020) 21, 78. https://doi.org/10.1038/s41432-020-0120-8 